CLINICAL STUDY

\title{
Long-term outcome following interstitial laser photocoagulation of benign cold thyroid nodules
}

\author{
Helle Døssing, Finn Noe Bennedbæk ${ }^{1}$ and Laszlo Hegedüs ${ }^{2}$ \\ Department of Oto-Rhino-Laryngology and Neck Surgery, Odense University Hospital, DK-500O Odense C, Denmark, ${ }^{1}$ Department of Endocrinology and \\ Metabolism, Herlev University Hospital, Herlev, Denmark and ${ }^{2}$ Department of Endocrinology and Metabolism, Odense University Hospital, \\ Odense, Denmark \\ (Correspondence should be addressed to H Døssing; Email: helle.doessing@ouh.regionsyddanmark.dk)
}

\begin{abstract}
Aim: To evaluate the long-term efficacy of interstitial laser photocoagulation (ILP) in solitary benign thyroid nodules.

Design and methods: A total of 78 euthyroid outpatients (45 participating in randomized trials) with a benign solitary solid and scintigraphically cold thyroid nodule causing local discomfort were assigned to ILP. ILP (using one laser fiber) was performed under continuous ultrasound (US) guidance and with an output power of 1.5-3.5 W. Thyroid nodule volume was assessed by US and thyroid function determined by routine assays, before and during follow-up. Pressure symptoms and cosmetic complaints were evaluated on a visual analogue scale $(0-10 \mathrm{~cm})$. Of the total patients, six had thyroid surgery 6 months after ILP and three were lost to follow-up. The median follow-up for the remaining 69 patients was 67 months (range 12-114).

Results: The overall median nodule volume decreased from $8.2 \mathrm{ml}$ (range 2.0-25.9) to $4.1 \mathrm{ml}$ (range $0.6-33.0 ; P<0.001$ ) at the final evaluation, corresponding to a median reduction of $51 \%$ (range: -194 to $95 \%$ ). This correlated with a significant decrease in pressure as well as cosmetic complaints. After 12-96 months (median 38 months) of ILP, 21 patients (29\%) had thyroid surgery because of an unsatisfactory result. All had benign histology. Thyroid function was unaltered throughout and side effects were restricted to mild local pain.

Conclusion: US-guided ILP results in a satisfactory long-term clinical response in the majority of patients with a benign solitary solid cold thyroid nodule. Further large-scale studies should aim at optimizing selection criteria for ILP, preferably in randomized studies.
\end{abstract}

European Journal of Endocrinology 165 123-128

\section{Introduction}

Benign nodular thyroid disease is common in the adult population (1). Thyroid carcinoma is rare, and using a careful approach including clinical, biochemical, and ultrasonographic evaluation, as well as ultrasound (US)-guided fine needle aspiration biopsy, the need of diagnostic thyroidectomies can be reduced profoundly $(2,3)$. It follows that, dependent on patient preference, nonsurgical management may be considered (4).

Previously, ultrasound (US)-guided percutaneous ethanol injection (PEI) therapy has been introduced as a nonsurgical option. However, limitations related to seepage of ethanol causing serious side effects and lack of evidence of long-term efficacy have questioned the suitability of PEI for ablation of solid thyroid nodules (5-7). Radiofrequency (RF) is another technique used for thermal ablation. Its nodule volume-reducing effect varies (8-14), but largely the effect is comparable to that of interstitial laser photocoagulation (ILP) and PEI.
So far, there are no long-term follow-up studies evaluating the efficacy of RF-therapy. In theory, highintensity-focused ultrasound should be feasible. However, the available experience is restricted to a patient with a toxic thyroid nodule (15).

ILP is yet another technique used for thermal tissue ablation. By using low-power laser, the energy can be delivered in a controlled fashion with no or only minimal damage to the surrounding tissue $(16,17)$. Therefore, ILP has been introduced for ablation of benign solid cold thyroid nodules $(16,18-22)$. The procedure is performed on an outpatient basis, is well tolerated, and nodule volume reduction is comparable to that obtained following PEI $(5,23)$. ILP has proven a safe and effective procedure for inducing thyroid nodule necrosis. However, as for PEI, long-term efficacy data after ILP therapy for the time being are limited (24). Therefore, we evaluated nodule volume and nodule-related symptoms in a consecutive group of patients treated with ILP and followed, on average, for more than 5 years $(18,21,22)$. 


\section{Materials and methods}

From 1999 to 2008, 78 (45 participating in randomized trials) euthyroid outpatients (74 women; median age 46 years, range: $23-71$ ) with a solitary solid and scintigraphically cold thyroid nodule were assigned to ILP therapy. Cytology was compatible with a benign colloid nodule in all patients. All patients reported pressure symptoms and/or cosmetic complaints. None had suspicion of or a family history of thyroid cancer and none had had prior radiation to the neck. All patients were euthyroid and had normal serum calcitonin levels. Blood tests included serum TSH (normal range $0.3-4.0 \mathrm{mU} / \mathrm{ml}$ ) determined by DELFIA (Wallac OY, Turku, Finland), serum total thyroxine $\left(\mathrm{T}_{4}\right.$; normal range $65-135 \mathrm{mmol} / \mathrm{l})$ determined by RIA (Diagnostic Products Corp., Los Angeles, CA, USA), and serum total triiodothyronine $\left(\mathrm{T}_{3}\right.$; normal range $1.00-2.10 \mathrm{mmol} / \mathrm{l}$ ) determined by RIA (Johnson \& Johnson, Clinical Diagnostics Ltd, Amersham, UK). Free $\mathrm{T}_{4}\left(\mathrm{FT}_{4}\right)$ and Free $\mathrm{T}_{3}\left(\mathrm{FT}_{3}\right)$ indices were calculated by multiplying serum $\mathrm{T}_{4}$ and $\mathrm{T}_{3}$ levels by the percent $\mathrm{T}_{3}$ resin uptake. Serum antithyroid peroxidase antibodies (anti-TPOAb) were determined by RIA DYNO test (Brahms diagnostica GMBH, Berlin, Germany, normal range $<60 \mathrm{U} / \mathrm{ml}$ ). Of the 78 patients, 45 participated in randomized studies $(21,22)$, of which 15 were given up to three ILP sessions (22).

A Logiq 500 US scanner (GE Medical Systems, Milwaukee, WI, USA) with a $12 \mathrm{MHz}$ linear transducer (type 739L) mounted with a needle steering device for precise US-guided punctures was used. Under sterile conditions, and guided by US, the laser fiber $(0.4 \mathrm{~mm}$ in diameter) was positioned in the thyroid nodule through the lumen of an 18 gauge $(1.2 \mathrm{~mm})$ needle and preceded by local anesthesia with lidocaine $(10 \mathrm{mg} / \mathrm{ml})$. The needle was withdrawn $20 \mathrm{~mm}$ leaving the end of the fiber in direct contact with the tissue and at a distance from the neurovascular bundle of at least $1.5 \mathrm{~cm}$, to avoid injury to these structures. Therefore, deeply located nodules and nodules in proximity of the carotid vessels were not offered ILP.

Patients were then treated with an output power of 1.5-3.5 W, dependent on pre-treatment nodule volume and the position of the nodule. The entire procedure was performed under continuous US guidance. The laser power source was provided from a continuous wave infrared $(820 \mathrm{~nm})$ diode (model 15; Diomed, Cambridge, England) laser. During laser treatment, the necrosis of the tissue was clearly visible on US as an irregular echogenic area enlarging over time and the procedure was terminated when this area was stationary in size. Then, the laser fiber was placed in another part of the nodule until accessible parts of the nodule had been treated. ILP was carried out on an outpatient basis. Thyroid nodule volume was calculated on the basis of an ultrasonic scanning procedure, by recording cross sections through the gland $(5.5 \mathrm{MHz}$ static compound scanner type 1846, B\&K Medical, Gentofte, Denmark and LOGIQ 9 mounted with a 3D tracer; GE Medical System, both with an intra-observer variation of $\sim 5 \%)$. The nodule volume was calculated before treatment and subsequently during the follow-up.

Thyroid function was determined by routine assays before ILP and at each follow-up, and pressure and cosmetic complaints before, at 6 months, and at the final investigation were evaluated on a visual analogue scale $(0-10 \mathrm{~cm})$.

\section{Statistical analysis}

Statistical analyses were performed using SPSS Statistical Software program, version 18.0 (SPSS, Inc., Chicago, IL, USA). Continuous data are given as median and range. All comparisons for paired data are based on ANOVA II (observations based on within-subject difference; serial measurements; $\mathrm{TSH}$ and $\mathrm{FT}_{4}$ and $\mathrm{FT}_{3}$ indexes). Correlation among the energy deposited, initial nodule volume, and nodule volume reduction at the end of the follow-up was investigated by means of Spearman's rank correlation and regression analysis. Pressure symptoms and cosmetic complaints were rated on a $0-10 \mathrm{~cm}$ visual analogue scale and compared with the initial score and changes were evaluated by a sign test. A $P$ value $<0.05$ was considered significant.

\section{Results}

The overall median nodule volume decreased from $8.2 \mathrm{ml}$ (range 2.0-25.9) to $3.5 \mathrm{ml}$ (range 0.6-17.6) after 12 months $(P<0.001)$ and to $4.1 \mathrm{ml}$ (range $0.6-33.0 \mathrm{ml} ; P=0.001)$ at the final evaluation. At this time, median reduction was $51 \%$ (range -194 to $95 \%$ ). The median treatment duration of ILP was $900 \mathrm{~s}$ (range 292-2400). The overall median energy deposited was $2100 \mathrm{~J}$ (range 438-7200) corresponding to $242 \mathrm{~J} / \mathrm{ml}$ nodule tissue (range 21-960). There was no significant correlation between thermal energy deposited per milliliter nodule tissue and absolute nodule volume reduction $(r=0.17 ; P=0.15$; Fig. $1 \mathrm{~A})$. Regression analysis, with the initial nodule volume as a dependent variable and the absolute nodule volume reduction as an independent factor, demonstrates that the initial nodule volume cannot predict the outcome after ILP therapy $(r=-0.12 ; P=0.29)$, but there seems to be a trend towards a larger effect in nodules smaller than $10 \mathrm{ml}$ (Fig. 1B). The median treatment duration was $900 \mathrm{~s}$ (range: 292-2400 s). The median deposited energy was $2100 \mathrm{~J}$ (range 438-7200), corresponding to $242 \mathrm{~J} / \mathrm{ml}$ nodule tissue (range 21-960), and administered via one laser fiber. A total of 21 patients, who were treated for more than $900 \mathrm{~s}$, had two or three monthly ILP sessions. There was no correlation between 

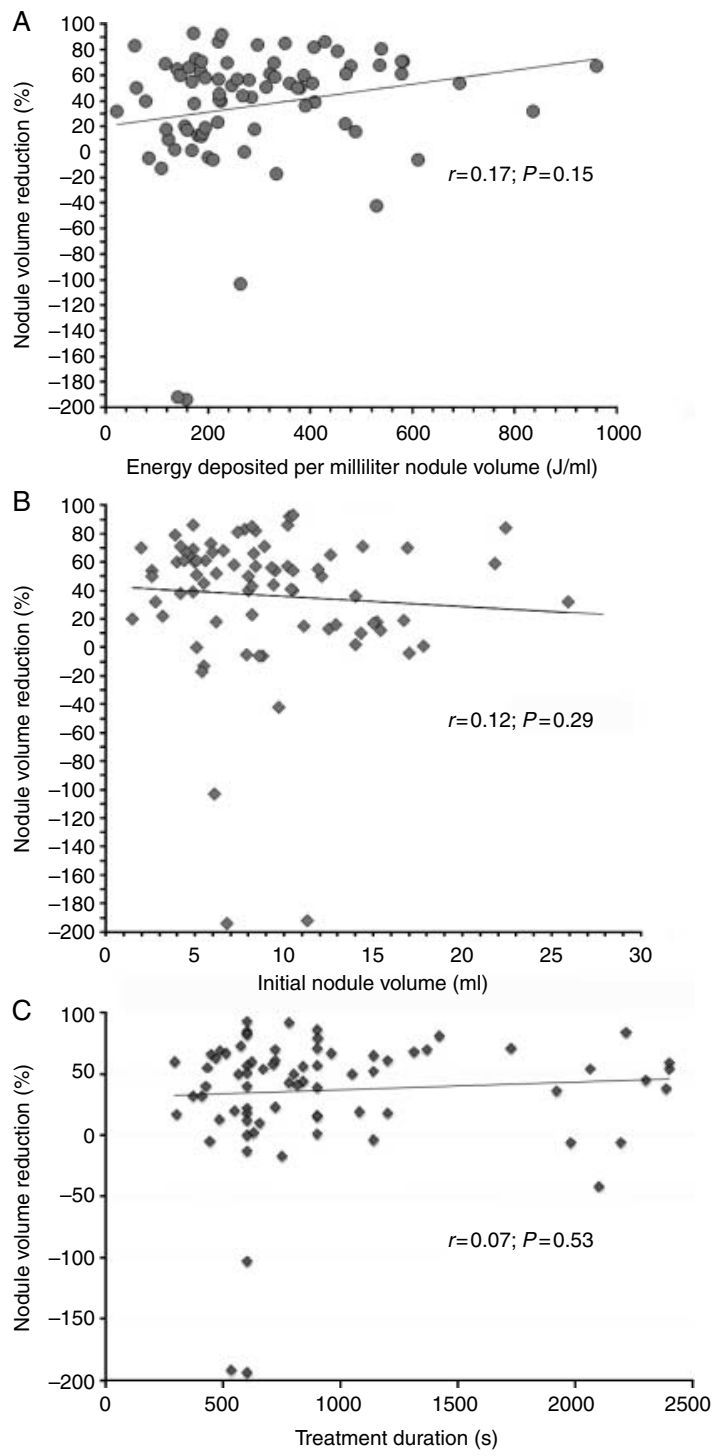

Figure 1 (A) Nodule volume reduction in relation to energy deposited per milliliter nodule tissue in 78 patients with a solid, scintigraphically cold thyroid nodule. No statistically significant correlation was found. (B) Initial nodule volume in relation to absolute nodule volume reduction in the 78 patients treated with ILP. No statistically significant correlation between initial nodule size and the degree of reduction was found. (C) Nodule volume reduction in relation to treatment duration. No statistically significant correlation was recorded.

treatment duration and nodule volume reduction $(P=0.53$; Fig. 1C).

Of the 78 patients, six had thyroid surgery 6 months after ILP and three were lost to follow-up. The median follow-up for the remaining 69 patients was 67 months (range 12-114 months). Furthermore, 21 patients had thyroid surgery 12 to 114 months (median 38 months) after ILP because of an unsatisfactory result. All patients had benign histology. The initial median nodule volume in the 27 patients who had thyroid surgery was $10.5 \mathrm{ml}$ (range 4.4-17.8). This significantly differs from the remaining 51 patients who had a median nodule volume of $6.6 \mathrm{ml}$ (range $1.5-25.9 ; P=0.001$ ). The median energy deposited per milliliter nodule volume in these patients was $195 \mathrm{~J} / \mathrm{ml}$ (range 79-612 J/ml) and in patients not operated on the median energy deposited was $285 \mathrm{~J} / \mathrm{ml}$ (range 21-960 J/ml); this difference was statistically borderline significant $(P=0.09)$. The overall median nodule volume reduction in the 27 patients who had thyroid surgery was 13\% (range - 194 to $61 \%$ ) compared with a reduction of $60 \%$ (range -13 to $93 \%$ ) in the other 51 patients. Of the 15 patients, who were offered up to three ILP sessions, three patients had surgery. Outcome in this group did not significantly differ from the outcome in patients who were offered one treatment session $(P=0.23)$.

Initially, 74 of 78 patients had pressure symptoms. Self-estimated pressure symptoms disappeared in $84 \%$ (62 of 74) of the patients. Initially, 46 of 78 patients had cosmetic complaints and the self-estimated complaints disappeared in $72 \%$ (33 of 46) of the patients (Fig. 2). Both the self-reported pressure symptoms $(r=0.4$; $P=0.02)$ and the cosmetic complaints $(r=0.3$; $P=0.02)$ significantly correlated with nodule volume reduction after ILP (Fig. $3 \mathrm{~A}$ and $\mathrm{B}$ ).

The median initial total thyroid volume in all 78 patients was $24.8 \mathrm{ml}$ (range 2.0-76.0), and at the final evaluation, it was $20.5 \mathrm{ml}$ (range 2.9-75.0; $P=0.037$ ). There was no significant change in serum TSH $(P=0.35)$ or anti-TPOAb $(P=0.32)$ during follow-up (data not shown).

The only side effect reported was moderate pain in $33 \%$ lasting for up to 4 days and alleviated with mild analgesics in all. None developed vocal cord palsy, hypocalcemia, hypothyroidism, local infection, or a

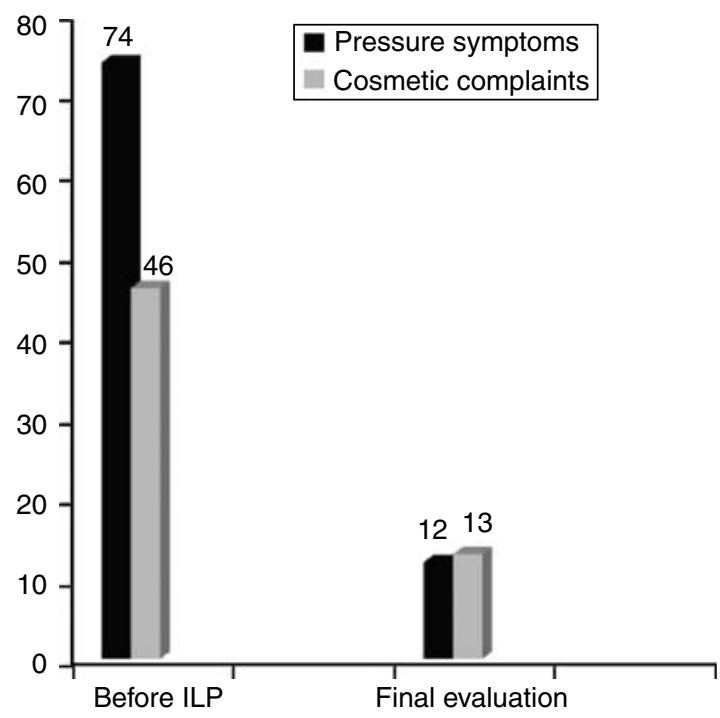

Figure 2 Number of patients with pressure symptoms and cosmetic complaints at enrollment and at the final evaluation. 

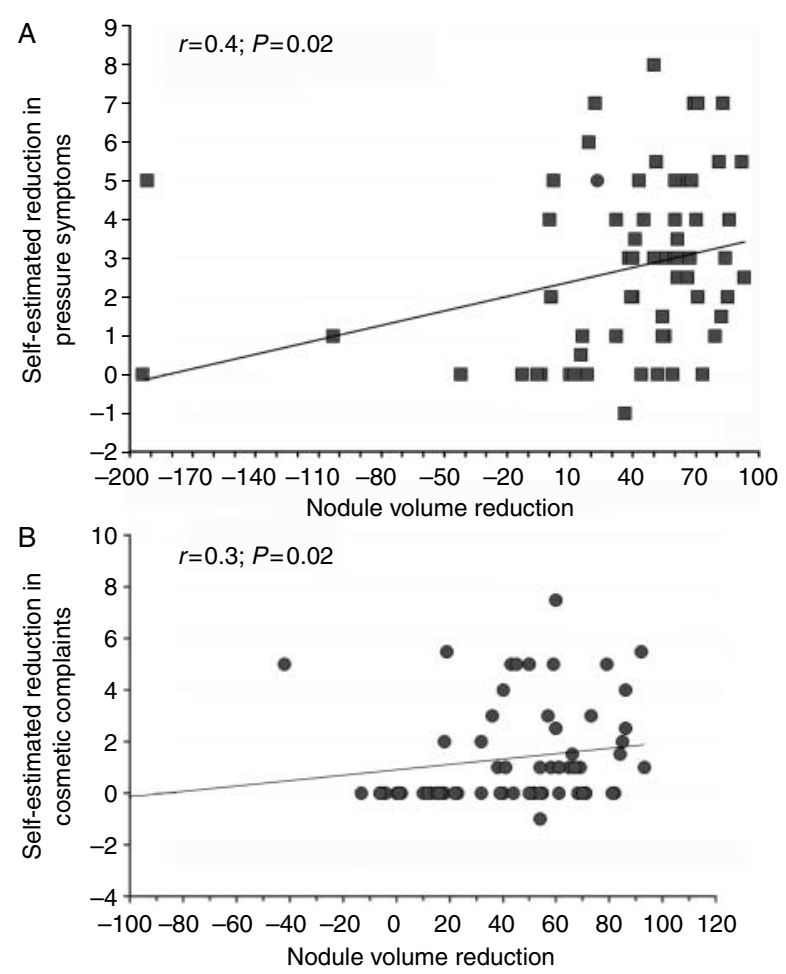

none or only minimal damage to the surrounding tissue $(16,17)$. Therefore, the advantage of ILP is the great precision in inducing a well-defined area of tissue ablation with a reproducible pattern as also confirmed by histological examination $(32,33)$. In extension to the lack of a histological gold standard, one potential disadvantage is the lack of total tissue ablation after ILP therapy. Although the termination of treatment during each session was guided by achieving a decreased and often obliterated vascularization within the nodule, the question of long-term efficacy, as evidenced by regrowth in case of only partial nodule reduction, remains unanswered for the time being. So far, only one study with a 3-year follow-up after ILP has been published (24). In that study, nodules were larger (mean $23 \mathrm{ml}$ ), patients with multinodular goiter were included, and the setup differed in several ways from ours. It was a more complicated and cumbersome setup employing a concept of multiple (up to four) fiber placement and multiparametric continuous monitoring of the electrocardiogram, oxygen tension, blood pressure, respiratory frequency, and also involved light conscious i.v. sedation. Moreover, at variance with our study, posttherapy treatment included methyl-prednisolone in every patient and analgesics were routinely given i.v. None of our patients had any i.v. treatment before or after ILP therapy, and all left our department within $10 \mathrm{~min}$ of therapy without further observation. In the study by Valcavi et al. (24), 50\% nodule volume reduction was achieved at the 3-year follow-up independently of initial size but a trend toward larger effect in the smallest nodules. However, a treatment protocol employing simultaneous placement of multiple fibers and treating larger nodules implies a larger risk of side effects and complications (24). This has to be taken into consideration when offering ILP as a non-surgical alternative.

In our long-term follow-up study, the median nodule volume reduction was $51 \%$, and this is comparable to the results of Valcavi et al. (24) using a much more elaborate design. Although the energy deposited per milliliter nodule tissue has varied in the available studies, a statistically significant correlation between energy deposited and nodule volume reduction could not be demonstrated $(18,21,22)$, and only few studies have been able to demonstrate such a correlation $(34,35)$. This suggests that in the individual patient, it is not easy to determine the optimal energy level. Thus, occasionally, low energy levels may cause significant nodule reduction (36).

The outcome after ILP is unpredictable. An explanation for this might be the wide variability in thyroid morphology. Biological characteristics such as vascularization of the nodule (it is well known that increased blood flow will result in increased disposal of thermal energy), the degree of pre-existing fibrosis, and the amount of colloid may be important factors accounting for the differences in optical properties of thyroid 
nodules, thereby differences in and unpredictability of responsiveness. Consequently, although we aimed at achieving a very homogeneous group of patients, nodules may have considerably varied and to some extent explain the unpredictable effect of therapy. Pretreatment nodule size, in this follow-up study, was not significantly correlated with the degree of nodule volume reduction after ILP; however, a trend was demonstrated and nodules smaller than $10 \mathrm{ml}$ seem to have a slightly better outcome. This is in agreement with the results of others (36), suggesting that nodule size, in extension to the optical properties of thyroid nodules, may be another factor influencing the ILP efficacy.

Of the 78 patients, 27 (35\%) had thyroid surgery because of an unsatisfactory result after ILP therapy (mainly persistent or worsening pressure symptoms and/or regrowth of the nodule). The median initial nodule volume in these 27 patients was $10.5 \mathrm{vs} 6.6 \mathrm{ml}$ in the 51 patients, who had no surgery. Most of these patients were operated in the early period of our studies, at which time we were hesitant to observe the patients and rapidly chose surgery if there was little or no nodule shrinkage. Importantly, surgery - as the gold standard confirmed the cytologically benign nature of all these nodules. Compensating for the nodule size, in order to increase thermal necrosis, a beam-splitting device, using two or even more laser fibers simultaneously as well as increased output power, has been suggested (24). An output power of $5 \mathrm{~W}$ induces burning pain during ILP therapy (20), increases the risk of carbonization of the fiber, and transient vocal cord palsy has been described, when more than one fiber has been used $(19,20)$. Another potential major disadvantage, when using more than one fiber, is a poorer real-time US overview of the actual extent of thermal necrosis, because only a two-dimensional picture is provided and also because the increased acoustic shadowing results in less clear margins of the thermally induced damage. For these reasons, but also because increasing the deposited energy seems to have only limited effect on volume reduction, it is not obvious to use several fibers, at least in small- to moderate-sized nodules (14).

The ILP treatment was well tolerated and the only side effect was less to moderate pain for up to 1 week in a few patients $(18,21,22)$. The self-estimated rating of discomfort related to the ILP therapy varied among the patients, but the fact that all but one patient would accept a repeat treatment, if offered later, confirms the tolerability as opposed to PEI (37). Pain or discomfort associated with the therapy disappeared in those few patients reporting of it, when the energy was turned off. Replacing the fiber into another area or decreasing the output power resulted in prompt relief of discomfort. Strictly speaking, therapy-induced thyroid autoimmunity following thermal ablation and due to release of thyroglobulin was not ruled out. For this, determination of thyroglobulin antibodies should have also been included. We, however, believe that an unaltered level of TSH together with lack of alteration in TPOAb positivity suggests this to be unlikely.

In conclusion, ILP is a minimally invasive procedure causing no or only minimal damage to the normal perinodular tissue. It is a relatively low-cost procedure, is easy to control, and results in a satisfactory long-term (median 67 months) clinical response in the majority of but not all patients with a benign solitary solid cold thyroid nodule. It is a clinically relevant alternative to surgery in selected patients. The disadvantage is that the procedure is highly operator dependent and does not provide a definitive histological assessment compared to surgery. At present, the study populations are small and further large-scale studies should aim at optimizing selection criteria for ILP therapy and evaluate costbenefit, preferably in randomized studies with surgery and/or other nonsurgical options as the comparator.

\section{Declaration of interest}

The authors declare that there is no conflict of interest that could be perceived as prejudicing the impartiality of the research reported.

\section{Funding}

This research did not receive any specific grant from any funding agency in public, commercial or not-for-profit sector. However, L Hegedüs is the recipient of an unrestricted grant from the Novo Nordisk Foundation.

\section{References}

1 Hegedüs L, Bonnema SJ \& Bennedbæk FN. Management of simple nodular goiter: current status and future perspectives. Endocrine Reviews 200324 102-132. (doi:10.1210/er.2002-0016)

2 Alexander EK, Heering JP, Benson CB, Frates MC, Doubilet PM, Cibas ES \& Marqusee E. Assessment of nondiagnostic ultrasoundguided fine needle aspirations of thyroid nodules. Journal of Clinical Endocrinology and Metabolism 200287 4924-4927. (doi:10. 1210/jc.2002-020865)

3 Hegedüs L. Clinical practice. The thyroid nodule. New England Journal of Medicine 2004351 1764-1771. (doi:10.1056/ NEJMcp031436)

4 Gharib H, Papini E, Paschke R, Duick DS, Valcavi R, Hegedüs L \& Vitti P. American Association of Clinical Endocrinologists, Associazione Medici Endocrinologi, and European Thyroid Association medical guidelines for clinical practice for the diagnosis and management of thyroid nodules: executive summary of recommendations. Journal of Endocrinological Investigation 201033 $51-56$.

5 Bennedbæk FN \& Hegedüs L. Percutaneous ethanol injection therapy in benign solitary solid cold thyroid nodules: a randomized trial comparing one injection with three injections. Thyroid 19999 225-233. (doi:10.1089/thy.1999.9.225)

6 Papini E, Pacella CM \& Verde G. Percutaneous ethanol injection (PEI): what is its role in the treatment of benign thyroid nodules? Thyroid 19955 147-150. (doi:10.1089/thy.1995.5.147)

7 Gharib H, Papini E \& Paschke R. Thyroid nodules: a review of current guidelines, practices, and prospects. European Journal of Endocrinology 2008159 493-505. (doi:10.1530/EJE-08-0135)

8 Baek JH, Moon WJ, Kim YS, Lee JH \& Lee D. Radiofrequency ablation for the treatment of autonomously functioning thyroid nodules. World Journal of Surgery 200933 1971-1977. (doi:10. 1007/s00268-009-0130-3) 
9 Baek JH, Kim YS, Lee D, Huh JY \& Lee JH. Benign predominantly solid thyroid nodules: prospective study of efficacy of sonographically guided radiofrequency ablation versus control condition. AJR. American Journal of Roentgenology $20101941137-1142$. (doi:10.2214/AJR.09.3372)

10 Deandrea M, Limone P, Basso E, Mormile A, Ragazzoni F, Gamarra E, Spiezia S, Faggiano A, Colao A, Molinari F \& Garberoglio R. US-guided percutaneous radiofrequency thermal ablation for the treatment of solid benign hyperfunctioning or compressive thyroid nodules. Ultrasound in Medicine and Biology 200834 784-791. (doi:10.1016/j.ultrasmedbio.2007.10.018)

11 Jeong WK, Baek JH, Rhim H, Kim YS, Kwak MS, Jeong HJ \& Lee D. Radiofrequency ablation of benign thyroid nodules: safety and imaging follow-up in 236 patients. European Radiology $2008 \mathbf{1 8}$ 1244-1250. (doi:10.1007/s00330-008-0880-6)

12 Kim YS, Rhim H, Tae K, Park DW \& Kim ST. Radiofrequency ablation of benign cold thyroid nodules: initial clinical experience. Thyroid 200616 361-367. (doi:10.1089/thy.2006.16.361)

13 Spiezia S, Garberoglio R, Di SC, Deandrea M, Basso E, Limone PP, Milone F, Ramundo V, Macchia PE, Biondi B, Lombardi G, Colao A \& Faggiano A. Efficacy and safety of radiofrequency thermal ablation in the treatment of thyroid nodules with pressure symptoms in elderly patients. Journal of the American Geriatrics Society $2007 \mathbf{5 5}$ 1478-1479. (doi:10.1111/j.1532-5415.2007.01306.x)

14 Spiezia S, Garberoglio R, Milone F, Ramundo V, Caiazzo C, Assanti AP, Deandrea M, Limone PP, Macchia PE, Lombardi G, Colao A \& Faggiano A. Thyroid nodules and related symptoms are stably controlled two years after radiofrequency thermal ablation. Thyroid 200919 219-225. (doi:10.1089/thy.2008.0202)

15 Esnault O, Rouxel A, Le NE, Gheron G \& Leenhardt L. Minimally invasive ablation of a toxic thyroid nodule by high-intensity focused ultrasound. AJNR. American Journal of Neuroradiology 201031 1967-1968. (doi:10.3174/ajnr.A1979)

16 Pacella CM, Bizzarri G, Guglielmi R, Anelli V, Bianchini A, Crescenzi A, Pacella S \& Papini E. Thyroid tissue: US-guided percutaneous interstitial laser ablation - a feasibility study. Radiology 2000217 673-677.

17 Prapavat V, Roggan A, Walter J, Beuthan J, Klingbeil U \& Muller G. In vitro studies and computer simulations to assess the use of a diode laser $(850 \mathrm{~nm})$ for laser-induced thermotherapy (LITT). Lasers in Surgery and Medicine 199618 22-33. (doi:10.1002/ (SICI)1096-9101(1996)18:1 < 22::AID-LSM3 > 3.0.CO;2-T)

18 Døssing H, Bennedbæk FN, Karstrup S \& Hegedüs L. Benign solitary solid cold thyroid nodules: US-guided interstitial laser photocoagulation - initial experience. Radiology 2002225 53-57. (doi:10.1148/radiol.2251011042)

19 Spiezia S, Vitale G, Di Somma C, Assanti AP, Ciccarelli A, Lombardi G \& Colao A. Ultrasound-guided laser thermal ablation in the treatment of autonomous hyperfunctioning thyroid nodules and compressive nontoxic nodular goiter. Thyroid 2003 13 941-947. (doi:10.1089/105072503322511346)

20 Pacella CM, Bizzarri G, Spiezia S, Bianchini A, Guglielmi R, Crescenzi A, Pacella S, Toscano V \& Papini E. Thyroid tissue: US-guided percutaneous laser thermal ablation. Radiology 2004 232 272-280. (doi:10.1148/radiol.2321021368)

21 Døssing H, Bennedbæk FN \& Hegedüs L. Effect of ultrasoundguided interstitial laser photocoagulation on benign solitary solid cold thyroid nodules - a randomised study. European Journal of Endocrinology 2005152 341-345. (doi:10.1530/eje.1.01865)

22 Døssing H, Bennedbæk FN \& Hegedüs L. Effect of ultrasoundguided interstitial laser photocoagulation on benign solitary solid cold thyroid nodules: one versus three treatments. Thyroid 2006 16 763-768. (doi:10.1089/thy.2006.16.763)

23 Bennedbæk FN, Nielsen LK \& Hegedüs L. Effect of percutaneous ethanol injection therapy versus suppressive doses of L-thyroxine on benign solitary solid cold thyroid nodules: a randomized trial. Journal of Clinical Endocrinology and Metabolism $1998 \mathbf{8 3}$ 830-835. (doi:10.1210/jc.83.3.830)
24 Valcavi R, Riganti F, Bertani A, Formisano D \& Pacella CM. Percutaneous laser ablation of cold benign thyroid nodules: a 3-year follow-up study in 122 patients. Thyroid $2010 \mathbf{2 0}$ 1253-1261. (doi:10.1089/thy.2010.0189)

25 Bennedbæk FN, Karstrup S \& Hegedüs L. Percutaneous ethanol injection therapy in the treatment of thyroid and parathyroid diseases. European Journal of Endocrinology 1997136 240-250. (doi:10.1530/eje.0.1360240)

26 Døssing H, Bennedbæk FN \& Hegedüs L. Ultrasound guided interstitial laser photocoagulation of an autonomous thyroid nodule - the introduction of a novel alternative. Thyroid 200313 885-888. (doi:10.1089/105072503322401104)

27 Zingrillo M, Torlontano M, Ghiggi MR, Frusciante V, Varraso A, Liuzzi A \& Trischitta V. Radioiodine and percutaneous ethanol injection in the treatment of large toxic thyroid nodule: a longterm study. Thyroid 200010 985-989. (doi:10.1089/thy.2000. 10.985)

28 Cakir B, Topaloglu O, Gul K, Agac T, Aydin C, Dirikoc A, Gumus M, Yazicioglu K, Ersoy RU \& Ugras S. Effects of percutaneous laser ablation treatment in benign solitary thyroid nodules on nodule volume, thyroglobulin and anti-thyroglobulin levels, and cytopathology of nodule in $1 \mathrm{yr}$ follow-up. Journal of Endocrinological Investigation 200629 876-884.

29 Papini E, Guglielmi R, Bizzarri G \& Pacella CM. Ultrasound-guided laser thermal ablation for treatment of benign thyroid nodules. Endocrine Practice 200410 276-283.

30 Bennedbæk FN \& Hegedüs L. Treatment of recurrent thyroid cysts with ethanol: a randomized double-blind controlled trial. Journal of Clinical Endocrinology and Metabolism $2003 \mathbf{8 8} 5773-5777$. (doi:10.1210/jc.2003-031000)

31 Zingrillo M, Collura D, Ghiggi MR, Nirchio V \& Trischitta V. Treatment of large cold benign thyroid nodules not eligible for surgery with percutaneous ethanol injection. Journal of Clinical Endocrinology and Metabolism 199883 3905-3907. (doi:10. 1210/jc.83.11.3905)

32 Law P, Gedroyc WM \& Regan L. Magnetic resonance-guided percutaneous laser ablation of uterine fibroids. Journal of Magnetic Resonance Imaging 200012 565-570. (doi:10.1002/1522-2586 (200010)12:4< 565::AID-JMRI8 > 3.0.CO;2-4)

33 Sanden H \& Hauptmann G. Laser application for minimal invasive reduction of thyroid gland tissue. European Journal of Medical Research 19972 527-534.

34 Gambelunghe G, Fatone C, Ranchelli A, Fanelli C, Lucidi P, Cavaliere A, Avenia N, d'Ajello M, Santeusanio F \& De FP. A randomized controlled trial to evaluate the efficacy of ultrasound-guided laser photocoagulation for treatment of benign thyroid nodules. Journal of Endocrinological Investigation 200629 RC23-RC26.

35 Papini E, Guglielmi R, Bizzarri G, Graziano F, Bianchini A, Brufani C, Pacella S, Valle D \& Pacella CM. Treatment of benign cold thyroid nodules: a randomized clinical trial of percutaneous laser ablation versus levothyroxine therapy or follow-up. Thyroid 200717 229-235. (doi:10.1089/thy.2006.0204)

36 Amabile G, Rotondi M, De CG, Silvestri A, Di FB, Bellastella A \& Chiovato L. Low-energy interstitial laser photocoagulation for treatment of nonfunctioning thyroid nodules: therapeutic outcome in relation to pretreatment and treatment parameters. Thyroid 200616 749-755. (doi:10.1089/thy.2006.16.749)

37 Hegedus L. Therapy: a new nonsurgical therapy option for benign thyroid nodules? Nature Reviews. Endocrinology 20095 476-478. (doi:10.1038/nrendo.2009.152)

Received 24 April 2011

Accepted 4 May 2011 